\title{
Era uma vez um sexto ano: estudando imaginação adolescente no contexto escolar
}

\author{
Aline Vilarinho Montezi \\ Vera Lúcia Trevisan de Souza
}

\begin{abstract}
Resumo
A partir de uma perspectiva crítica que concebe o adolescente com grande potencial de criação desde que encontre contexto propício ao seu desenvolvimento, o presente estudo objetivou investigar a imaginação enquanto ferramenta para a configuração de novos sentidos pelos adolescentes em relação à escola, ao ensino e à aprendizagem. Assumem-se, como referencial teórico-metodológico, os pressupostos da psicologia histórico-cultural, sobretudo os de Vigotski. A pesquisa foi realizada com alunos do $6^{\circ}$ ano do ensino fundamental de uma escola pública da rede municipal de uma cidade do interior de São Paulo e utilizou histórias como materialidade mediadora. As informações foram organizadas em cinco núcleos de significação, como forma de analisar os sentidos investigados. Como resultados, evidencia-se a importância de investir na imaginação como ferramenta no processo de ensino e aprendizagem e como meio de dar voz aos adolescentes, realizando uma educação em que o aluno é sujeito e protagonista de sua história.
\end{abstract}

Palavras-chave: Imaginação, adolescência, psicologia histórico-cultural.

\section{Once upon a time there was a sixth grade class: studying teenagers's imagination in school context}

\begin{abstract}
Starting from a critical perception that conceives the adolescent with great potential of creation as long as there is a proper development context, in this work we aim at investigating imagination as a new senses configuration tool for the adolescents in relation to school, education, and learning. We take as theoretical-methodological references the historical-cultural psychology presuppositions, particularly Vigotski's. The research was conducted with 6th grade students in a public elementary school in a city in the countryside of São Paulo State. We used reports as materiality mediator. Information was categorized into five cores of meaning in order to analyze the investigated senses. The results reveal the importance of using imagination as a tool in the education and learning processes and as means of giving adolescents voice, accomplishing an education method in which the students are the protagonists of their own history.
\end{abstract}

Key-words: Imagination, adolescence, historic-cultural psychology.

\section{Érase una vez un sexto año: estudiando la imaginação adolescente en contexto escolar}

\begin{abstract}
Resumen
Desde una perspectiva crítica, que comprende el adolescente con gran potencial de creatividad desde que encuentre contexto propicio a su desarrollo, el presente estudio tuvo el objetivo de investigar la imaginación como herramienta para la configuración de nuevos sentidos por los adolescentes en relación a la escuela, a la enseñanza y al aprendizaje. Se asumen como referencial teórico-metodológico los supuestos de la Psicología Histórico-Cultural, especialmente los de Vigotski. La investigación se realizó con alumnos del $6^{\circ}$ año de la enseñanza fundamental de una escuela pública de la red municipal de una ciudad del interior de São Paulo y utilizó historias como materialidad mediadora. Las informaciones fueron organizadas en cinco núcleos de significación como forma de analizar los sentidos investigados. Como resultado se destaca la importancia de considerar la imaginación como herramienta en el proceso de enseñanza y aprendizaje y como medio de dar voz a los adolescentes, realizando una educación en que el alumno es sujeto y protagonista de su historia.
\end{abstract}

Palabras clave: Imaginación, adolescencia, psicología histórico-cultural. 


\section{Introdução}

Este artigo apresenta alguns resultados de uma pesquisa-intervenção, realizada no âmbito do mestrado, que teve como objetivo estudar a imaginação de adolescentes, tomando por base os pressupostos teórico-metodológicos de Vigotski. Ela é parte de um conjunto de investigações desenvolvidas pelo Grupo de pesquisa "Processos de constituição do sujeito em práticas educativas", que abrangem diversos contextos em que se desenvolvem práticas sociais voltadas à educação.

A abundância de estudos voltados à adolescência (Benincasa, Rezende, \& Coniaric, 2008; Oliveira \& Gomes, 2012; Vieira, Freitas, Pordeus, Lira, \& Silva, 2009) revela que um olhar cuidadoso a esse momento do desenvolvimento é fundamental. Segundo esses estudos, a frequente naturalização dessa fase e as atribuições de rebeldes, conflituosos e transgressores de regras aos adolescentes acentuam características estigmatizantes que desvalorizam os jovens na sociedade e promovem a manutenção de relacionamentos conturbados e prejudiciais a eles. Essa visão, segundo Ozella e Aguiar (2008), tem assumido maiores proporções a partir da década de 1990.

Somam-se a essas questões apontadas pelos estudiosos do tema nossas experiências em intervenções e pesquisas desenvolvidas em escolas públicas de ensino fundamental, em que observamos o desinteresse dos adolescentes pelas práticas escolares, principalmente as relativas ao ensino de conteúdos, por um lado; e as queixas de docentes sobre o que denominam ora de "apatia", ora de "indisciplina" ou "falta de respeito", por outro (Souza \& Petroni, 2010; Souza, Andrada, \& Petroni, 2011, no prelo). Essas constatações parecem justificar a necessidade de se investigar outros aspectos da adolescência, em específico os relativos ao potencial criativo dos jovens, de modo a oferecer contribuições que favoreçam a construção de um ambiente escolar propício ao desenvolvimento saudável. Para tal, elegeu-se como problemática de investigação da pesquisa ora apresentada o papel da imaginação na constituição de jovens, em específico nas relações que envolvem a aprendizagem na escola.

No que concerne à imaginação, a revisão bibliográfica realizada evidencia um aumento de investigações sobre o tema nos últimos anos. Na base de dados do Scielo, constam 38 artigos indexados nos últimos três anos. Os artigos das áreas de Educação e Psicologia justificam o interesse pela temática por conceberem a imaginação como condição para a criatividade e, portanto, de fundamental importância não só como ferramenta de ensino, mas também como manifestação da subjetividade (Girardello, 2011; Oliveira \& Stoltz, 2010; Serra, 2009).

No campo da Psicologia, são muitos os estudos que investigam a criatividade nos processos de ensino e aprendizagem, de perspectivas teóricas diversas, focalizando a educação básica, o ensino superior, as práticas docentes, os estilos de aprendizagem, as estratégias de criação, as competências criativas, dentre outros (Nakano \& Wechsler,
2007). O estudo de Nakano e Wechsler se propôs a identificar as características da produção científica sobre o tema da criatividade no Brasil, no extenso período de 1984 a 2006, por intermédio da revisão de dissertações e teses constantes da base de dados da CAPES e de artigos publicados em periódicos indexados no Index-psi, caracterizando-se, portanto, como estado da arte. As autoras localizaram 104 teses e dissertações, além de 95 artigos. Observaram que foram mais frequentes estudos com adultos e adolescentes, a maioria na área educacional. Em relação ao aporte teórico-metodológico, Nakano e Wechsler (2007) identificam a prevalência de correntes mais tradicionais da Psicologia, tais como a psicometria (34\%) e a psicanálise $(21 \%)$. Estudos que se declaram como de base histórico-cultural ou crítico correspondem a apenas $4 \%$.

Mais recentemente, no entanto, têm aumentado os estudos e a proposição de práticas escolares sobre criatividade da perspectiva da psicologia histórico-cultural, por concebê-la como favorecedora da aprendizagem e desenvolvimento (Mitjánz Martinez, 1997, 2004, 2006).

Ante o exposto, entendemos que abordar a criatividade como função psicológica superior, mobilizada pela imaginação, articulada a outras funções, tal como a concebe Vigotski (1990, 1996, 1999, 2009), pode trazer contribuições para a compreensão e promoção do desenvolvimento de adolescentes, sobretudo em contextos de ensino e aprendizagem. Adota-se, portanto, a compreensão da imaginação de uma perspectiva dialética que, a um só tempo, é produtora e produto da atividade criadora do homem.

Vigotski (1990) explica a atividade criadora como um processo que envolve várias funções psicológicas, tais como: a percepção, quando alguns aspectos da realidade são tomados como significativos pelo sujeito e armazenados na memória; a imaginação, quando há a reelaboração dos elementos percebidos e armazenados na memória por meio da fantasia; e a objetivação do produto da imaginação, que apresenta uma nova qualidade do percebido (Vigotski, 1990,1996, 1999, 2009).

Para Vigotski (2009), existem dois tipos de atividade: a reconstituidora ou reprodutiva, relacionada à memória, que repete aquilo que anteriormente existia; e a combinatória ou criadora, que consiste em criar novas imagens ou ações. Assim, a imaginação é uma função psicológica vital e necessária que constrói quatro tipos de relação com a realidade.

A primeira é a de que toda obra da imaginação tem como base elementos apreendidos da realidade e presentes na experiência anterior da pessoa, ou seja, quanto mais rica a experiência, mais elementos estão disponíveis à sua imaginação; a segunda se refere à articulação entre o produto final da fantasia e um fenômeno complexo da realidade. Por exemplo, ao ver um quadro ou escutar uma história, a pessoa não se limita às experiências passadas, mas cria novas combinações. A terceira forma é de caráter "emocional": todo o sentimento e emoção tende a se entrelaçar com imagens conhecidas correspondentes a esse sentimento, de modo que a emoção parece possuir a capacidade de selecionar impressões, ideias e imagens consoantes a um determinado 
instante. A quarta e última forma tem como essência a construção da fantasia como algo inusitado, sem ter relação com experiências anteriores da pessoa ou algum objeto existente. Mas, ao adquirir concretude material, essa "imaginação cristalizada começa a existir realmente no mundo e influir sobre outras coisas" (Vigotski, 2009, p. 28).

Essas considerações assumem relevância ao se focalizar a adolescência, quando a imaginação assume prevalência no modo de ser e agir do sujeito. Para Vigotski (2009), nesse momento acontece uma intensa reestruturação da imaginação, pois "de subjetiva ela se transforma em objetiva" (p. 48). A "crise" que se costuma associar à adolescência nada mais é que a formação do organismo e do cérebro adultos e o antagonismo entre a subjetividade pura da imaginação e a objetividade dos processos racionais. Essas relações antitéticas são, para Vigotski, o que define a idade de transição como crítica.

\section{Método}

O presente trabalho tomou por base a psicologia histórico-cultural, que postula o sujeito como complexo, constituído nas e pelas relações empreendidas no contexto. Trata-se de lançar o olhar para além do evidente, do que se expressa, rumo à explicação dos fenômenos e não apenas à descrição do observável (Souza, 2004)

A pesquisa-intervenção foi realizada com quatro turmas dos $6^{\circ} \mathrm{S}$ anos do ensino fundamental de uma escola pública da rede municipal de uma cidade do interior de São Paulo. As turmas tinham entre 28 e 32 alunos cada, na faixa etária de 11 a 14 anos. A escola é campo de estudos e intervenção do grupo de pesquisa a que se vincula este trabalho desde 2007. No início de 2010, fomos chamados à escola para atender a uma queixa em relação aos $6^{\circ}$ anos: segundo os professores, havia problemas de relacionamento, principalmente de exclusão de alunos com necessidades especiais. Entretanto, depois de algumas observações, percebemos que não se tratava de uma questão pontual envolvendo alunos com necessidades especiais. O que ocorria eram atitudes que expressavam falta de atenção ou concentração de modo generalizado e desinteresse pelas propostas dos professores ou pela realização das atividades, com falas excessivas, movimentação pela sala enquanto se deveria dedicar à lição, provocações aos professores e colegas etc., dificultando o andamento das aulas e provocando grande desconforto aos professores e mesmo aos colegas.

Diante do que observamos, propusemos à escola realizar uma intervenção com os grupos, em que utilizaríamos como estratégia a contação de histórias. Essa atividade, além de agilizar a imaginação, podendo despertar o interesse dos jovens, exige atenção e concentração, a regulação da fala e da escuta e, ao longo de sua realização, investigaríamos o que estaria na base das atitudes observadas e objeto da queixa dos professores.
Aceita a proposta, fomos apresentadas ao professor Sérgio ${ }^{1}$, que ministrava uma disciplina voltada às reflexões sobre a contemporaneidade e tinha a preocupação de inovar nas estratégias que utilizava em suas aulas. Estabelecemos, então, uma parceria no planejamento e realização das atividades de intervenção. Duas etapas foram construídas para viabilizar a pesquisa-intervenção. Na primeira, foram realizadas observações das aulas durante um mês, a fim de obter maiores informações sobre as relações e nos aproximarmos dos alunos e professor. A segunda etapa consistiu na "contação de histórias". É importante considerar que a opção em utilizar esse recurso se sustenta em nosso pressuposto teórico. Segundo Vigotski (2009), na adolescência, a forma pela qual a imaginação se manifestava na infância, como o desenho, por exemplo, desaparece, dando lugar à criação literária, que, para o autor, é estimulada pela "ascensão das vivências subjetivas, pela ampliação e pelo aprofundamento da vida íntima do adolescente, de tal maneira, que nessa época, constitui-se nele um mundo específico" (p.49). A contação de histórias também se relaciona à nossa hipótese no estudo de que muitas das atitudes observadas decorriam da falta de sentido para os alunos das práticas oferecidas em sala de aula. Conforme já afirmamos, a história, por sua estrutura e conteúdo, agiliza a imaginação. Ao narrar diversos casos e situações, as histórias oferecem infinitas possibilidades de significação e atribuição de sentidos, a depender da experiência de cada sujeito.

Entretanto, é preciso investir no modo de contar, modificando o meio físico, criando um cenário e um clima que desperte o interesse do ouvinte. Em relação ao tipo de histórias, pensamos, inicialmente, em trabalhar com temas que se aproximassem do cotidiano deles. Ao consultar a literatura voltada ao público juvenil, encontramos os contos de Heloísa Prieto no livro Balada, retratando uma série de histórias sobre um mesmo personagem, Sebas, um adolescente de 13 anos, vivendo diferentes situações com sua turma de amigos. O procedimento consistia em contar a história e conversar sobre ela em seguida.

A primeira história, contada no segundo encontro, tratava da problemática de um adolescente que não conhecia o pai, o que resultou em identificação por parte dos alunos, uma vez que muitos não conheciam o pai biológico, somente o padrasto. Já no terceiro encontro, a história versava sobre um adolescente que estava gostando da sua melhor amiga. Os alunos ficaram evolvidos na discussão e em vários momentos se dirigiram ao professor Sérgio perguntando sobre suas namoradas quando jovem. Vale ressaltar que, no quarto encontro dessa etapa, fui surpreendida por um movimento de desinteresse dos alunos. Refletindo sobre a razão de tal desinteresse, levantamos a hipótese de que talvez se devesse ao fato de as histórias tratarem de temas muito próximos à realidade dos alunos, o que, ao contrário do que pretendíamos, não estaria provocando o potencial imaginativo de cada um e nem se abrindo à possibilidade de criação, mantendo-os no relato de situações que viviam

1 Para preservar a privacidade dos participantes, foram utilizados nomes fictícios. 
no cotidiano. Observando o relacionamento entre os alunos em outros momentos, percebi que era frequente a menção a filmes e personagens de histórias de terror. Decidi, então, mudar o tipo de história e investir mais cuidadosamente na criação do cenário. Passei a utilizar histórias de terror voltadas ao público jovem e adotei um jogo de luzes, sombras e escuridão, além de sonoplastia com clima de suspense.

Já na primeira história de terror eles permaneceram interessados durante o encontro todo. Ao final, contaram animadamente histórias de terror que conheciam. Diante da disposição de muitos em contar histórias, sugeri que passássemos a gravar em áudio o que contavam, ao que aderiram, e, nos encontros seguintes, além de ouvir minha história e contar a deles, também ouvíamos juntos as gravações.

No sexto encontro fiz mais uma modificação: propus contar a história até a metade e eles deveriam continuá-la. Após escurecer a sala, comecei a contar uma história de Sebas - personagem das histórias iniciais -, que se aventurava com os amigos na visita a um cemitério à noite, e terminei com a seguinte frase: "Era muito assustador...". Gravamos as histórias e ouvimos no final do encontro.

O sétimo encontro aconteceu após duas semanas de férias. Como havíamos combinado com o professor Sérgio, não poderíamos utilizar todas as aulas do semestre e, portanto, o encerramento do projeto deveria ser iniciado. Planejamos o encerramento, propondo aos alunos escrever um livro. Sugeri que contássemos as histórias, gravássemos, e eu as transcreveria para que, na semana seguinte, começássemos o livro. E trabalhamos nele nos dois encontros seguintes. Os alunos sugeriram expor o livro na feira do livro, quando seria nosso último encontro dessa etapa. Pouco mais de um mês depois, aconteceu a feira do livro, e eles apresentaram a história no ginásio esportivo para todas as pessoas presentes na escola. Estavam radiantes, cheios de orgulho com os elogios dos alunos, dos professores e dos gestores.

Com o intuito de não perder a complexidade do vivido com os alunos nos momentos de contação de história, trabalhei com uma parceria nas intervenções, uma colega que fazia o registro minucioso do que acontecia, o qual era trabalhado, logo em seguida, em forma de diário de campo, quando eu acrescentava o que havia sentido e percebido às informações registradas. O diário de campo, as gravações em áudio e os textos escritos pelos alunos constituíram o que chamei de "construção da informação", tal como propõem Aguiar e Ozella (2006). Após organizar o material, procedi a uma leitura cuidadosa, mas ainda de caráter geral, buscando palavras ou expressões-chave, ou seja, que se relacionassem aos objetivos da pesquisa. Essa busca visava identificar momentos em que os conteúdos sobre a escola, a aprendizagem, a imaginação e a adolescência se revelassem, de alguma forma, importantes para os alunos.

Já na segunda leitura, procurei aglutinar conteúdos semelhantes a partir das palavras ou expressões previamente identificadas. Essa aglutinação poderia ser feita por similaridade, complementaridade ou contraposição. Isso é o que Gonzalez Rey chama de indicadores (2002, 2003, 2005). Por indicadores, podem-se entender os "elementos que adquirem significação graças à interpretação do pesquisador, ou seja, sua significação não é acessível de forma direta à experiência, nem aparece em sistemas de correlação" (Gonzalez Rey, 2002, p. 112). Por essa razão, esse processo de aglutinação inicial serviu à elaboração de uma forma de compreender os processos investigados.

Organizados os indicadores, procedemos à construção dos núcleos de significação, conforme proposto por Aguiar e Ozella (2006). O processo consistiu em nomear os conteúdos que haviam sido aglutinados a partir de uma nova análise, para apresentar o que seria essencial dos aspectos analisados. Segundo os autores, é nesse momento que o refletir passa do empírico para o interpretativo, e assim se faz necessária a relação, a comparação, a reelaboração e a discussão da base teórica com as informações elaboradas durante o processo da pesquisa.

\section{Resultados}

Em consonância com o aporte teórico adotado, utilizamos como procedimento de análise a elaboração de núcleos de significação, de modo a apreender os sentidos atribuídos às vivências com as histórias pelos alunos. Segundo Aguiar e Ozella (2006), "O sentido coloca-se em um plano que se aproxima mais da subjetividade, que com mais precisão expressa o sujeito, a unidade de todos os processos cognitivos, afetivos e biológicos" (p. 5). Para se compreender os sentidos, afirmam esses autores, é necessário analisar as determinações constitutivas do sujeito, como, por exemplo, o reconhecimento e compreensão dos modos de agir, de sentir e de pensar dos participantes envolvidos na pesquisa.

Para os propósitos deste artigo, apresentamos, a seguir, a análise de cinco núcleos de significação, quais sejam: 1 - Assumir-se como autor é fazer emergir o sujeito singular; 2 - A imaginação mobilizada pela experiência dos jovens; 3 - Imaginação mobilizada pelas emoções; 4 - A imaginação na elaboração de emoções e sentimentos - a emoção real mobilizada pelo irreal; e 5 - O reconhecimento do potencial do sujeito mobiliza sua imaginação na construção de sua autoria.

\section{Assumir-se como autor é fazer emergir o sujeito singular}

Esse núcleo de significação resulta da aglutinação de indicadores de sentidos que emergem do envolvimento dos jovens com a contação de histórias, quais sejam: a necessidade dos alunos de serem vistos, considerados e escutados em seus saberes, experiências e necessidades. Esses sentidos podem derivar do modo como se configuram as relações em sala de aula, nas quais parece prevalecer a centralidade do professor e dos conteúdos, não havendo espaço para a expressão dos alunos, de suas singularidades e emergência como autores de suas histórias. 
Autoria aqui entendida como possibilidade de ser sujeito, tal como propõe Gonzalez Rey (2004), que define sujeito como aquele que "se exerce na legitimidade de seu pensamento, de suas reflexões e das decisões por ele tomadas" (p. 149), sendo capaz de atuar de maneira reflexiva e produzir novos processos de subjetivação. Para o autor, há duas possibilidades de ação para o indivíduo: sujeitar-se às várias ordens que institucionalizam os espaços de suas esferas de ação, ou ser capaz de criar alternativas singulares de socialização nesses espaços.

Nas situações observadas na escola, no entanto, parece improvável a criação de espaços que facilitem a emergência do sujeito. Se, como diz Vigotski (2009), a adolescência é o momento da fertilidade da criatividade, dos pensamentos, por que não explorar essas funções psicológicas superiores enquanto ferramentas para promover o desenvolvimento e a aprendizagem? Por que não investir na superação desse "assujeitamento", que contribui para a promoção da exclusão por meio do abandono da escola ou da alienação de seus processos de aprendizagem?

Parece que os adolescentes clamam por atenção, por um olhar mais cuidadoso e implicado com suas histórias, com seus modos de pensar e de agir. É isso que se observa no trecho a seguir:

Num determinado momento, alguns meninos migraram para as extremidades da sala e se ESCONDIAM na hora de falar o nome. Continuei falando que gostaria de saber como se chamavam, e foi interessante porque, quando eu olhava bem nos olhos deles e perguntava o nome, eles pareceriam ficar satisfeitos e falavam! (DC n. 03 - Maio 2010).

Desde o primeiro momento, fiz questão de saber o nome de cada um, para que de fato sentissem que naquele espaço seriam respeitados e valorizados. Mas esse movimento já era realizado pelo professor Sérgio, que conhecia cada um dos alunos e se preocupava em atendê-los de modo que correspondesse às expectativas deles. Ainda que consideremos o dialético presente no processo de apropriação da realidade pelo sujeito, parece-nos extremamente inadequado o modo como tem se constituído a escola no que concerne à relação que empreende com os alunos, sobretudo os adolescentes.

A intervenção permitiu um movimento de reconhecimento: quando perceberam que haveria espaço, eles cada vez mais queriam se ouvir, pois percebiam que tinham algo a dizer, que podia ser muito interessante se expressar por terem as opiniões valorizadas:

Todos bateram palmas e quiseram escutar a história, já que eu tinha gravado. Ficaram em silêncio absoluto e gostaram de se escutar. (DC n. 08- Junho 2010)

Cristiano disse que Sebas, o protagonista da história, tinha o talento do pai. Daniel disse que, assim como Sebas, tinha o talento de desenhar. Maria disse que tinha o talento de tocar violão, cavaquinho, gaita... Perguntei se havia mais talentos e eles disseram que não. Daniel disse que compôs uma música em parceria com a menina que toca para outra menina, falando sobre a feiura dela, pois era muito chata. (D.C. n. 04 - Maio 2010).

É interessante considerar que o envolvimento dos alunos para a construção do livro aconteceu gradativamente, à medida que se sentiam "autores" da história. O apoio proporcionado nas intervenções para se colocarem enquanto autores permitiu que conquistassem mais espaços na escola:

Antes de apresentarem, outros eventos aconteceram, como a dança do grupo de Hip Hop. Leandro disse que gostaria de apresentar o livro no palco, falando a história no microfone, juntamente com Vicente. Então foram os alunos com quem eu havia combinado ao palco. Muitas pessoas assistiram, inclusive, os membros da gestão. Vicente contava fervorosamente a história. Rafaela se vestiu com as roupas do teatro e se maquiou para a apresentação do livro! Todos contavam as histórias, com intensidade! (DC n. 12 - Outubro 2010).

O movimento de autoria dos alunos aconteceu de maneira expansiva, pois, num dos maiores eventos da escola, a "Feira do Livro", eles não se contentaram em deixar o livro exposto para que as pessoas pudessem ler, sentiram necessidade de ir ao palco e contar a história a todos os presentes.

\section{A imaginação mobilizada pela experiência dos jovens}

Esse núcleo de significação se organiza a partir dos seguintes indicadores de sentidos: as expressões dos jovens se baseiam e se organizam em torno de suas experiências; a realidade concreta é a base para seus processos de produção simbólica; e a agilização de sua imaginação requer o investimento em experiências simbólicas. Assim, a expressão dos alunos revela parte de seu universo simbólico, e o contato com esses símbolos e sua elaboração mobiliza sonhos e ações. Esse processo acontece como uma recombinação dos elementos da realidade, que resulta em novas significações, movimento que, para Vigotski (2009), é uma das formas de relação da imaginação com a realidade.

Após as apresentações, propus que nomeássemos nosso grupo. As sugestões eram nomes da "moda", que todos ouviam, divulgados pela mídia: "Parangolê" (nome do grupo que canta rebolation, uma música da moda); "Psy" (estilo de música que eles gostavam de dançar), "Leite Quente" (personagem de um programa humorístico da rede globo). Na votação, ganhou o nome "Psy". (DC n. 03 - Maio 2010).

É possível notar a influência da mídia na vida cotidiana dos jovens, de onde derivam elementos para a atividade 
de criar um nome para o grupo. Observa-se, assim, sua dimensão mobilizadora de sentidos, o que fica claro na escolha pelos jovens de um nome que os represente e os torne reconhecidos. A sensação de reconhecimento encontra na imaginação uma possibilidade na produção e elaboração de sentidos:

Pedro disse que deveríamos ter uma mascote. Perguntei o que achavam e todos concordavam. Perguntei o que significava uma mascote, e eles disseram que era um animal e já propôs um gavião, a mascote do Corinthians. (DC $n$. 04 - Maio 2010)

O interesse dos alunos e seu envolvimento com as propostas de criar situações e eventos novos, tais como formas de denominar a atividade que realizávamos pela singularização de cada grupo e uma imagem que os representasse e diferenciasse, revelaram seu potencial para a simbolização, que exige um processo de síntese, mediado pela imaginação. Essa constatação nos levou a questionar o que chamamos de certa desvalorização dos processos imaginativos na escola: por que não fazer uso da imaginação que, na adolescência, favorece o acesso a modos de pensar mais abstratos, tal como define Vigotski (1996), e apareceu na capacidade de simbolização dos alunos?

Acreditamos que é necessário ao professor rever sua postura. Se permanecer na condição de detentor do saber, sem se abrir aos conhecimentos e potencialidades dos alunos, na melhor das hipóteses, o conhecimento vai ser apenas assimilado e reproduzido, dadas as poucas oportunidades de os alunos acessarem novas experiências, não podendo, portanto, mobilizá-las para um modo mais criativo de aprender e pensar.

\section{Imaginação mobilizada pelas emoções}

Esse núcleo se constitui de dois indicadores de sentidos que abordaremos de modo peculiar. $O$ primeiro diz respeito ao fato de que o interesse na atividade agiliza a imaginação e a criatividade pela combinação do que os alunos já conhecem ou experimentaram. O segundo se refere ao papel da emoção na imaginação, ou seja, investir na agilização da imaginação demanda considerar os aspectos afetivo e volitivo, constituintes das condutas humanas.

Mas o que estaria na base do interesse? Se remetermos aos dados, veremos que, no quarto encontro, foi utilizada uma história de terror, o que possibilitou aos adolescentes vivenciarem o medo.

Enquanto contava, todos reagiam. Diziam que estavam com medo. Pedro contou a história de um bebê amaldiçoado. Que a mãe fazia maldades com ele, era uma casa de família e, misteriosamente, aconteciam coisas com o bebê. Enquanto contavam as histórias, colocamos o som ao fundo e todos sentaram pertinho e escutaram. (DC n. 07 - Junho 2010).
O que estamos denominando de "interesse" está intrinsecamente relacionado à motivação, ou seja, aos desejos e emoções. Segundo Vigotski (1996), toda conduta humana é sustentada pela tendência afetivo-volitiva. Isso pode ser refletido na própria relação que os alunos estabelecem com os professores. Não é somente a matéria que desperta ou não o interesse deles, mas também o sentimento de gostar do professor, da maneira como o professor ensina, se investe ou não no ensino, a forma como são tratados, dentre outros.

Se remetermos ao contexto da intervenção, identificamos elementos que contribuíram para a construção de um vínculo positivo. Minha postura aberta e respeitosa frente a qualquer manifestação dos alunos e a presença constante do professor, legitimando a ação da psicóloga, permitiram que a confiança permeasse o espaço de relações construído. Mesmo surpreendida por um movimento de desinteresse dos alunos até esse dia, insisti na busca de algo que os interessasse. A história de terror, acompanhada de toda uma preocupação com a organização do espaço e sonoplastia adequada, mobilizou-os de fato, a ponto de expressarem seus sentimentos por meio de outras histórias no mesmo dia:

Vicente contou uma história (engraçado que, quando ele fala, todos fazem questão de escutar): "Foi há três mil anos". Quatro adolescentes foram acampar. Não havia nada no local, então um deles se lembrou de uma brincadeira... Era a do copo! Cada um falava o nome com o dedo no copo, fazia uma pergunta e este se movimentava conforme quisesse falar com uma das pessoas. Na hora que a última pessoa foi falar... BUUUUUUUUUMMM! (alguém bateu a porta da sala de aula de verdade! Vicente combinou com o amigo) Todos gritaram! (DC n. 07 - Junho 2010).

Além da ressignificação do espaço, nesse momento o processo de autoria começa a surgir, pela possibilidade de emergência do sujeito. O terror foi a base de muitas criações, inclusive a da história final para o livro, cujo enfoque era a conspiração dos educadores contra os alunos do $6^{\circ}$ ano. Ou seja, de alguma forma, esse medo pairava sobre eles, e uma tensão existia de fato no ambiente escolar:

Vicente: O nome dela era cuca... Todos os turistas que iam ao cemitério, ela matava, hipnotizava e não deixava ninguém entrar, porque ali tinham dois tesouros: um era esqueleto de pessoas e o outro era a varinha de condão que transformava as pessoas em estátuas e hipnotizava. Só que então o filho de quem estava naquela época descobriu que os pais existem. Ele foi o corajoso que entrou lá, ganhou uma capa invisivel da bruxa. Colocou-a e pegou a varinha de condão sem ela perceber, os diamantes também, e falou as palavras mágicas: TUMALACATUMASEBILINARATATUM!, que destruíram-na e nunca mais ela perambulou pelo cemitério e fim.(DC n. 08 - Junho 2010)

A realidade dizível pela imaginação confere voz ao adolescente e se torna, mais uma vez, uma ferramenta para 
a possibilidade de vivenciar emoções / sentimentos positivos e negativos.

\section{A imaginação na elaboração de emoções e sentimentos - a emoção real mobilizada pelo irreal...}

Esse núcleo remete ao seguinte indicador de sentidos: é possível experimentar emoções e compreendê-las com a segurança de que o que se vive não é real. Poder experimentar o medo com a segurança de não estar ameaçado, com a certeza de que não será julgado de modo depreciativo nos parece estar na base da grande mobilização dos jovens em se expressarem.

Muitas criações baseadas no terror foram realizadas pelos alunos, e isso aconteceu porque provavelmente se sentiram confortáveis para usar a imaginação com a segurança de que não haveria concretude completa para tanto terror:

\begin{abstract}
Era uma vez um castelo que havia pessoas mutantes e cada um tinha o seu poder. Era tipo uma escola de aprendizado e havia 31 alunos e cada um tinha um poder. Aí apareceu um professor invisível, o nome dele era Sérgio. Esse professor queria ajudar a classe, porque o $6^{\circ} \mathrm{C}$ era a classe mais encapetada, nem o diretor que era o mais poderoso não podia ver a sala. Aí o diretor chegou e falou: com tantas aberrações, resolvemos fazer uma reunião porque a classe do $6^{\circ} \mathrm{C}$ está muito terrível, nem eu que sou o diretor e tenho o poder maior do mundo não consigo controlar. Então eu peço para que os pais se manifestem. Aí o pai de um aluno levantou-se e disse: Diretor, por que o senhor não manda fazer um caixão para deixar os alunos ruins trancados durante um ano? E aí um pai que era um deus se manifestou e o chão tremeu: Nossos filhos têm que ficar nessa escola! (D.C. n. 08 - Agosto de 2010).
\end{abstract}

A criação dessa história para o livro, se recorrermos aos núcleos anteriores, está baseda em elementos da realidade. Uma tensão foi vivenciada na escola, principalmente com os alunos dessa classe, e, dialeticamente, ela atingiu os alunos. Nesse caso, a imaginação proporcionou uma maneira de elaborar a angústia, dando à fantasia uma nova direção.

Vigotski (2006), ao discorrer sobre a adolescência, faz menção ao fato de o jovem "sonhar desperto": quando isso acontece, há um poema imaginado, formado por partes "separadas", mais ou menos constantes, cheio de peripécias diversas, com variadas situações e episódios. Dessa forma, é possível construir um sonho criativo, produto da imaginação, que ele vive como se fosse realidade.

Sandro disse que os desenhos de Sebas se tornavam realidade. Perguntei se isso aconteceria de fato. Isabela disse que às vezes sim, que podemos mudar a realidade. Perguntei de que maneira, e Sabrina disse que podemos USAR A IMAGINAÇÃO! Perguntei o que era imaginação e ela disse que era uma maneira de criar, pensar e muitas outras coisas. (D.C. n. $04-31$ de Maio de 2010)

Essa ideia de uma profunda vinculação da imaginação com a realidade se contrapõe a uma concepção de imaginação como inata ou idealista, que está na base do que parece pairar na escola: "ficar imaginando é sair da realidade, 'viajar', não prestar atenção e não aprender. Para aprender é preciso ter os pés na realidade somente".

Se pensarmos em termos de estratégias educacionais, veremos que ainda há uma limitação da escola no que se refere a promover uma maneira de construir conhecimento que envolva o desprendimento da realidade concreta para um real concebido como diferentes ideias que podem ser reformuladas.

\section{O reconhecimento do potencial do sujeito mobiliza sua imaginação na construção de sua autoria}

O que estaria na base da criatividade observada nos alunos? Esse núcleo tem aglutinados os indicadores de sentidos relativos ao reconhecimento do potencial do sujeito como promotor da criatividade e a criatividade como, a um só tempo, produtora e produto da emergência do aluno como sujeito.

Vicente sugeriu um livro, enquanto os outros tinham ideias das partes do livro, como título, capa, e sugeriram que o livro falasse a respeito da sala do professor Sérgio. Vicente inventou a história e os outros complementavam, inclusive o professor Sérgio. (DC n. 09 - Agosto 2010)

Vigotski (2009), ao fazer menção aos mecanismos de uma imaginação criativa, se volta ao processo de "dissociação" e "associação". O primeiro consistiria em fragmentar um grande complexo em partes, bem como romper a relação natural segundo a qual estas foram percebidas. Com qual relação natural os alunos romperam? Se pensarmos na maneira tradicional das aulas na escola, com a qual eles estavam habituados, podemos inferir que as atitudes do professor Sérgio, com a preocupação em sempre inovar as próprias aulas, o respeito com que se referia aos alunos e à nossa parceria, criando espaço para que algo diferente e novo acontecesse, foram as facilitadoras para um rompimento de limitações à expressão desses jovens. De modo que eles se sentiram capazes para a autoria de um livro:

Fiz a proposta, eles logo organizaram as carteiras e os grupos. Alguns que estavam "alheios", após um tempo, se comprometeram a fazer uma parte da história e a capa. Engraçado que, conforme eles vão se envolvendo, se organizam para um fazer uma coisa, outro, outra, quem desenha melhor faz para ficar "mais bonito", enquanto o outro ESPERA para poder escrever, enfim, aconteceu toda uma mobilização para o livro.(DC n. 10 - Agosto 2010) 
Reconhecer o potencial criativo e a imaginação enquanto aliados para transcender os muros da realidade concreta e aceder a modos mais abstratos e generalizados de pensamento e ação permite um novo posicionamento no que se refere às responsabilidades, nesse caso, escolares. As maiores queixas e angústias referidas pelos docentes partem justamente da indiferença e descaso que os alunos apresentam durante as aulas, queixas que se revelam um paradoxo na medida em que se cobram participação, envolvimento, interesse e responsabilidade, mas não se abre à expressão singular de cada um, à emergência do sujeito, às possibilidades de autoria e autonomia.

\section{Conclusão}

A intervenção proposta abriu espaço para os alunos contarem suas histórias - nesse caso, fatos de suas vidas cotidianas. Esse era o interesse, despertado pela postura e proposta da pesquisadora. E foi possível detectar dois movimentos dos alunos frente a essa proposta: o desinteresse, que os impedia de fazer uso do espaço que lhes dava voz e de manifestar o desejo de escutar as histórias levadas pela pesquisadora; e a emergência deles enquanto sujeitos, autores da própria história.

Ambos os movimentos deram margem para alguns questionamentos: quando queremos o interesse dos adolescentes, o fazemos porque queremos lhes impor dado objeto? Como podem se interessar por ele? Queremos que eles falem como forma de manifestação de interesse e envolvimento, mas que falem do quê? Poderiam eles falar de algo que não fosse de seu universo?

Também não podemos deixar de colocar em evidência as dificuldades enfrentadas pelos professores, relacionadas à própria formação que recebem. Privilegiar o conhecimento intelectual, bem como a preocupação em cumprir o conteúdo programado, talvez seja um fator limitante do processo de construção de conhecimento. Não se trata de culpabilizá-los, mas compreendê-los.

Diante dessas considerações, vemos a importância de utilizar a imaginação como recurso nas estratégias de ensino e aprendizagem, a partir do momento em que ela se sustenta nas experiências concretas dos alunos e professores, e isso deve ser levado em conta quando pensamos na forma como se desenvolve o processo de aprendizagem. Não se trata de colocá-lo numa instância maior e distante, mas sim de valorizar o cotidiano e o contexto de cada um para que haja sentido no que está sendo estudado.

Do ponto de vista do papel do psicólogo no contexto escolar, vemos a importância de se analisar e acompanhar minuciosamente as práticas escolares, com foco nas relações e nos processos de ensino e aprendizagem, posicionando-se como parceiro do educador no oferecimento de conhecimentos sobre processos psicológicos relativos ao desenvolvimento e aprendizagem e no apoio às suas ações e demandas. Nesse sentido, deve oferecer oportunidades de reflexões conjuntas que possibilitem a construção de novas estratégias voltadas ao ensino e formação dos alunos. No caso desta pesquisa-intervenção, a parceria construída com o professor foi, sem dúvida, fundamental para o resultado positivo da intervenção. Em relação à contribuição da intervenção para o professor, no período em que permanecemos na escola, após finalizar o projeto de contação de histórias, observamos o professor utilizando algumas estratégias de nossas atividades, recriando-as pelo uso de filmes e adaptando-as ao conteúdo de sua disciplina. Essa experiência nos leva a afirmar que a inserção do psicólogo na escola e sua real contribuição para os processos de desenvolvimento e aprendizagem de alunos e professores só se efetivarão pela parceria com os profissionais desse contexto, o que demanda grande investimento não só em práticas psicológicas inovadoras como também na formação dos psicólogos.

Seria necessário, no entanto, investir em outros estudos que investigassem a concepção dos professores sobre a imaginação, seu conhecimento sobre processos psicológicos envolvidos na aprendizagem e a importância da criatividade na adolescência como potencial a ser explorado nos alunos. Também seria importante investigar de que modo a imaginação pode atuar na criatividade do docente e que dimensão ela ocupa em sua formação, inicial e continuada. Enfim, questões cujas respostas trariam contribuições à meIhoria da qualidade da educação básica.

\section{Referências}

Aguiar, W. J., \& Ozella, S. (2006). Núcleos de significação como instrumento para a apreensão da constituição dos sentidos. Revista Psicologia: ciência e profissão, 26(2), 222-245.

Benincasa, M., Rezende, M. M., \& Coniaric, J. (2008). Sexo desprotegido e adolescência: fatores de risco e proteção. Psicologia Teoria e Prática, 10(2), 121-134.

Girardello, G. (2011). Imaginação: arte e ciência na infância. ProPosições, 22(2), 72-92.

Gonzalez Rey, F. (2002). Pesquisa Qualitativa em Psicologia: caminhos e desafios. São Paulo: Pioneira Thonson Learning.

Gonzalez Rey, F. (2003). Sujeito e Subjetividade. São Paulo: Pioneira Thomson Learning.

Gonzalez Rey, F. (2004). O Social na Psicologia e a Psicologia Social. Petrópolis, RJ: Vozes.

Gonzalez Rey, F. (2005). Pesquisa Qualitativa e Subjetividade: os processos de construção de informação._São Paulo: Pioneira Thomson Learning.

Mitjáns Martinez, A. (1997). Criatividade, personalidade e educação. Campinas, SP: Papirus. 
Mitjáns Martinez, A. (2004). O outro e sua significação para a criatividade: implicações educacionais. Em L. M. Simão \& A. Mitjáns Martinez (Orgs), O outro no desenvolvimento humano (pp. 77-99). São Paulo: Thomson.

Mitjáns Martinez, A. (2006). Criatividade no trabalho pedagógico e criatividade na aprendizagem: uma relação necessária. Em M. C. R. V. Tacca (Org.), Aprendizagem e trabalho pedagógico (pp. 6994). Campinas, SP: Alínea.

Nakano, T. C., \& Wechsler, S. M. (2007). Criatividade: características da produção científica brasileira. Avaliação psicológica, 6(2), 261270.

Oliveira, M. E., \& Stoltz, T. (2010). Teatro na escola: considerações a partir de Vygotsky. Educação em Revista, 36, 77-93.

Oliveira, J. R., \& Gomes. M. A. (2012). Bullying: reflexões sobre a violência no contexto escolar. Revista Educação por escrito, 2(2), 1-13.

Ozella, S., \& Aguiar, V. M. J. (2008). Desmistificando a concepção de adolescência. Cadernos de Pesquisa, 38(133), 97-125.

Serra, D. J. G. (2009). Martí y la psicologia. Psicologia e Sociedade, 21(3), 358-363.

Souza, V. L. T. (2004). A interação na escola e seus significados e sentidos à formação de valores.Tese de Doutorado, Pontifícia Universidade Católica de São Paulo, São Paulo.

Souza, V. L. T.; Petroni, A. P. (2010) As relações na escola e a construção da autonomia. Psicologia e Sociedade, 22, 355-364.

Souza, V. L. T., Andrada, P. C., \& Petroni, A. P. (2011). Afetividade na escola: as demandas à psicologia educacional. VI Congresso
Internacional de Psicología y Educación (pp. 2377-2395). Valladolid, Espanha.

Souza, V. L. T., Andrada, P. C., \& Petroni, A. P. (no prelo). A afetividade como traço da constituição identitária docente: o olhar da Psicologia. Psicologia \& Sociedade.

Souza, V. L. T. (2010). Texto do método de pesquisa do grupo de pesquisa: Processos de Constituição do sujeito em práticas educativas (PROSPED) redigido por Vera Lúcia Trevisan de Souza.

Viera, L. J. E. S., Freitas, M. L. V. F., Pordeus, A. M. J., Lira, S. V. G., \& Silva, J. G. (2009). Amor não correspondido: discursos de adolescentes que tentaram suicídio. Ciência \& Saúde Coletiva, 14(5), 1825-1834.

Vigotski, L. S. (1990). La imaginacion Y el arte em la infância. Madrid: Akal.

Vigotski, L. S. (1996). Desarrollo de los interesses em la edad de transición. Em L. S. Vigotski, Vigotski Obras Escogidas IVPsicologia Infantil. Moscú: Editorial Pedagógica.

Vigotski, L. S. (1999). Sobre o problema da psicologia do trabalho criativo do ator. The collected works of L. S Vygotsky, 6, 237-244.

Vigotski, L. S. (2006). Pensamento e Linguagem. São Paulo: Martins Fontes.

Vigotski, L. S. (2009). A imaginação e a arte na infância: Ensaio Psicológico: livro para professores. São Paulo: Ática.

\section{Sobre as autoras}

Aline Vilarinho Montezi (alinemontezi@hotmail.com)

Mestranda em Psicologia e Bolsista Cnpq pela Pontifícia Universidade Católica de Campinas

Endereço: Rua Cristalina, número 26. Bairro Santa Esmeralda, Hortolândia, São Paulo.

Vera Lúcia Trevisan de Souza (vtrevisan@puc-campinas.edu.br)

Doutora em Psicologia da Educação Pela PUC-SP

Endereço: Rua Eduardo da Silva Magalhães, 77 - Pq Continental - SP - 05324000

Derivado da dissertação de mestrado 
